\title{
THE INFLUENCE OF THE 3-D MEDIA ON INDONESIAN LEARNING OUTCOMES OF GRADE II ELEMENTARY SCHOOL STUDENTS
}

\author{
Asmaliyatus Sholichah $^{1}$, Haris Supratno ${ }^{2}$, M. Bambang Edi Siswanto ${ }^{3}$ \\ ${ }^{1,2,3}$ Universitas Hasyim Asy'ari Tebuireng Jombang, Indonesia \\ asmaliyatussholichah@gmail.com, harissupratno@unesa.ac.id,mbambangedi@gmail.com
}

\begin{abstract}
The purpose of this study is to determine the effect of the use of 3-D learning media towards the student's Indonesian learning result of $2^{\text {nd }}$ grade students in SDI Sabilillah on the sketch material. The type of research used was Quasi Experiment. The subjects of the study were $2^{\text {nd }}$ grade students in SDI Sabilillah in year 2019/2020 which were divided into experimental class and control class. The results of the pretest and posttest tests conducted were obtained an average pretest result of 49.5 and an average posttest of 70.25 in the control class, and the average results of the pretest 50 and an average posttest of 80.25 in the experimental class. After the t test was performed on the pretest and posttest in the control class to get the results of $t_{\text {hitung }}>t_{\text {table }}$ or 3.67> 2.093 then $H_{o}$ was rejected and $H_{a}$ was accepted, so it could be concluded that there was a positive influence on the control class. $T$ test results in the experimental class were $t_{\text {hitung }}>t_{\text {table }}$ or $3.73>2.093$ then $H_{o}$ was rejected and $H_{a}$ was accepted, so it could be concluded that there was a positive influence on Indonesian language learning by using 3-D media. When it was compared to the $t$ test in the experimental class and the control class, namely (3.73)> (3.67) it could be seen that there was a difference between the experimental class using 3-D learning media and the control class using conventional learning, and the influence of using 3-D media were greater than conventional learning.
\end{abstract}

Keywords: 3-D learning media, learning results

\section{PENGARUH MEDIA TIGA DIMENSI TERHADAP HASIL BELAJAR BAHASA INDONESIA SISWA KELAS II SEKOLAH DASAR}

\begin{abstract}
ABSTRAK
Tujuan dari penelitian ini yakni mengetahui pengaruh penggunaan media pembelajaran tiga dimensi terhadap hasil belajar bahasa Indonesia siswa kelas II SDI Sabilillah pada materi denah. Jenis penelitian yang digunakaan adalah Quasi Eksperimen. Subjek penelitian yakni peserta didik kelas II SDI Sabilillah Tahun Ajaran 2019/2020 yang dibagi menjadi kelas eksperimen dan kelas kontrol. Hasil dari uji pretest dan postest yang dilakukan diperoleh hasil rata-rata pretest 49.5 dan rata-rata posttest 70.25 pada kelas kontrol, dan hasil rata-rata pretest 50 dan rata-rata posttest 80.25 pada kelas eksperimen. Setelah dilakukan uji t pada pretest dan posttest di kelas kontrol mendapatkan hasil $t_{\text {hitung }}>t_{\text {tabel }}$ atau $3.67>2.093$ maka $H_{o}$ ditolak dan $H_{a}$ diterima sehingga dapat disimpulkan bahwa terdapat pengaruh positif pada kelas kontrol. Hasil uji $t$ pada kelas eksperiment adalah $t_{\text {hitung }}>$ $t_{\text {tabel }}$ atau $3.73>2.093$ maka Ho ditolak dan Ha diterima, sehingga dapat disimpulkan bahwa terdapat pengaruh positif pada pembelajaran Bahasa Indonesia dengan menggunakan media tiga dimensi. Jika dibandingkan uji t pada kelas eksperimen dan kelas kontrol, yaitu (3.73) >(3.67) dapat dilihat bahwa terdapat perbedaan antara kelas eksperiment dengan menggunakan media pembelajaran tiga dimensi dan kelas kontrol dengan menggunakan pembelajaran konvensional, dan pengaruh penggunaan media pembelajaran tiga dimensi lebih besar daripada pada pembelajaran konvensional.
\end{abstract}

Kata Kunci: media pembelajaran tiga dimensi, hasil belajar

\begin{tabular}{|c|c|c|}
\hline Submitted & Accepted & Published \\
\hline 08 Agustus 2020 & 13 September 2020 & 28 September 2020 \\
\hline
\end{tabular}

\begin{tabular}{|l|l|r|}
\hline Citation & $:$ & $\begin{array}{r}\text { Sholichah, A., Supratno, H., \& Siswanto, M.B.E. (2020). The Influence Of The 3-D Media On Indonesian Learning } \\
\text { Outcomes Of Grade Ii Elementary School Students. Jurnal PAJAR (Pendidikan dan Pengajaran), 4(5), 1033- } \\
\text { 1039. DOI : http://dx.doi.org/10.33578/pjr.v4i5.8101. }\end{array}$ \\
\hline
\end{tabular}

\section{PENDAHULUAN}

Sekolah Dasar merupakan tempat belajar mengajar pada tahap awal yang berorientasi pada kebutuhan anak. Sehingga pengajaran sesuai dengan takaran yang telah ditentukan sebelumnya. Dalam prosesnya peserta didik dididik untuk menyiapkan sumber daya manuasia yang handal, kreatif dan inovatif. Di tahapan inilah dibentuk dasar-dasar keilmuan untuk penentuan keberhasilan pendidikan pada jenjang berikutnya. Agar tujuan pembelajaran tercapai, guru dan 
peserta didik harus saling bekerjasama agar menciptakan suasana kelas kondusif juga penerimaan materi yang cukup baik pada peserta didik. Dalam pengaplikasiannya belum sepenuhnya terlaksana dengan baik karena banyak perrmasalahan yaang diialami oleeh guuru maaupun pesserta diidik.

Pembelejaran Bahasa Indonesia adalah pelajaran yang disetiap sekolah ada. Mulai dari jenjang SD sampai SMA. Pada umumnya dalam pembelajaran bahasa Indonesia guru hanya menjelaskan panjang lebar karena bahasa Indonesia merupakan mata pelajaran yang memfokuskan pada kaidah-kaidah bahasa. Padahal pada kenyataannya beberapa materi dalam pembelajaran tersebut juga membutuhkan media pembelajaran.

Seorang guru dapat dikatakan kreatif dan inovatif jika guru dapat memadukan dan mengembangkan media pembelajaran sehingga, peran media pembelajaran dalam belajar mengajar dinilai sangat penting guna menunjang keberhasilan proses dan peserta didik mendapat hasil belajar yang diharapkan oleh guru. Aspek ini juga dapat mempermudah guru dalam menyampaikan pembelajaran kepada peserta didik dengan bantuan media pembelajaran.

Menurut Wati (2016: 3) meedia pembelajaran merupakan segala sesuatau yaang dapat memberikan pesan dan dapat merangsang kemauan, fikiran dan pesrasaan kepada seseorang sehingga mendorong dan memotivasi peserta didik dalam belajar. Media merupakan sesuatu yang melekat atau tidak bisa dipisah dari proses pembelajaran.

Sedangkan media tiga dimensi adalah suatu alat peraga yang mempunyai panjang, tinggi dan lebar serta dapat diamati dari sudut pandang mana saja (Nana Sudjana, 2011: 101). Penggunaan model tiga dimensi dalam pembelajaran untuk mengatasi keterbatasan benda nyata. Media tiga dimensi dirasa sangat menarik dan memotovasi peserta didik untuk belajar sehingga harapannya pembelajaran berjalan dengan lancar dan mudah serta membuahkan hasil yang maksimal dan diharapkan oleh guru. Jadi media pembelajaran tiga dimensi yakni alat peraga yang mempunyai bentuk fisik menyerupai benda nyata yang mempunyai panjang, tinggi dan lebar yang beruna untuk menunjang kegiatan pembelajaran.

Pada akhir pembelajaran peserta didik akan memperoleh hasil belajar dari keseluruhan pembelajaran yang telah ditempuhnya. Menurut Nana Sudjana (1989: 3) Penilaian proses hasil belajar Usaha pemeberian penilaian terhadap kegiatan pembelajaran yang dilakukakn oleh guru dan pesertadidik. Hasil belajar dapat berupa angka maupun huruf. Dapat diartikan bahwa hasil belajar yakni pelabelan atau pemberian angka maupun huruf diakhir pembelajaran sebagai tanda bahwa telah melakukan suatu proses pembelajaran.

Dari ulasan tersebut, maka penelitian ini dilakukan uji coba. Oleh karena itu disusunlah penelitian ini dengan judul "Pengaruh Media Pembelajaran Tiga Dimensi Terhadap Hasil Belajar Siswa Kelas II di SDI SABILILLAH Tahun Ajaran 2019/2020"

\section{KAJIAN TEORETIS}

Kajian pustaka pada penelitian yakni : (1) Media pembelajaran (2) Tiga dimensi (3) Hasil belajar (4) Tematik (5) Muatan Bahasa Indonesia. Menurut Schramm ( dalam Putri 2011: 20) media pembelajaran adalah alat pembawa pesan yang dapat bermanfaat bagi pembelajaran. Jadi media pembelajaran adalah bantuan alat yang berguna untuk pembelajaran. Media Pembelajaran merupakan alat perantara komunikasi antara guru dengan peserta didik dan digunakan dalam rangka mengefektifkn interaksi guru dan peserta didik dalam pembelajaran disekolah. Wati, Ega Rima (2016: 3). Kesimpulannya yakni media pembelajaran adalah segala sesuatu yang digunakan guru dalam menyampaikan informasi atau pesan kepada peserta didik yang bertujuan untuk membantu dalam proses belajar mengajar di dalam kelas. Media pembelajaran tidak bisa terpisah dari sebuah proses pembelajaran karena media menjadi unit kesatuan dalam pembelajaran yang sangat membantu dan menunjang pembelajaran dikelas yang mempengaruhi peserta didik untuk terus termotivasi dan tertarik dalam belajar. Jenis media pembelajaran meliputi: 1) 
Media visul 2) Adio visual 3) Komputer 4) Microsoft Power Point 5) Internet 6) Multimedia.

Menurut Sudjana (2011: 101) media tiga dimensi yang sering digunakan dalam pembelajaran yakni model. Model merupakan tiruan dari benda objek nyata yang ukurannya sedang, dan mudah dibawa dan digunakan di dalam kelas. Dapat diartikan bahwa tiga dimensi adalah benda yang mempunyai ukuran panjang,lebar dantinggi. Jadi media tiga dimensi yakni media tanpa proyeksiyangmenyerupai benda nyata yang dapat diamati dari semua sisi. Menurut Nana Sudjana (2010: 156) Model dalam tiga dimensi dibagi menjadi beberapa kategori sebagai berikut 1) Model Padat 2) Model Penampang 3) Model Susun 4) Model Kerja 5) Mockup 6) Diorama.

Hasil Belajar secara umum diartikan sebagai capaian yang diraih oleh peserta didik setelah mengikuti pembelajaran di kelas dan dapat dinyatakan dalam bentuk angka atau huruf. Menurut Bloom et al dalam Kurniawan, Deni (2014 : 10), hasil belajar dibedakan menjadi tiga yakni: 1) Hasil belajar kognitif 2) Hasil belajar psikomotorik 3) Hasil belajar afektif.

Menurut Kurniawan, Deni (2014 : 95) Tematik merupakan salah satu model dari pembelejaran terpaduyang memfokuskan pada materi yang dipadukan oleh tema. Tema dikembangkan dari luar mata pelajaran tetapi masih sejalan dengan standar isi materi. Jadi pembelajaran tematik merpakan pembelajaran tepadu yang mengintegrasikan beberapa mata pelajaran yang dipadukan dalam sebuah tema.

Pembelajaran Bahasa Indonesia di berikan disekolah dasar dengantujuan agar peserta didik dapat berbahasa Indonesia dengan baik dan benar serta bahasa yang digunakan sesuai dengan tingkatan peserta didik sekolah dasar. Peserta didik dapat berkomunikasi melalui lisan ataupun secara tulisan dengan bahasa yang baik dan benar sesuai kaidah yang berlaku. Terdapat emapat ketrampilan yang harus dikuasi oleh peserta didik yaitu; ketrampilan berbicara, ketrampilan membaca, ketrampilan menulis, ketrampilan menyimak.

Dari rumusan masalah, tujuan, teoriteori yang mendukung serta hasil penelitian sebelumnya, maka hipotesis yang diajukan adalah "Terdapat Pengaruh Positif Penggunaan Media Pembelajaran Tiga Dimensi Terhadap Hasil Belajar Bahasa Indonesia Kelas II SDI Sabilillah"

\section{METODE PENELITIAN}

Penelitian ini berbentuk penelitian eksperiment. Menurut Sugiyono(2016:6), memaparkan bahwametode penelitian eksperimen ialah matode penelitian yang digunakan untuk mencari pengaruh(treatment) perlakuan tertentu. Populasi dalam penelitian ini berjumlah 40 peserta sedangkan sampel yang digunakan berjumlah 20 peserta. Penelitian ini dilakukan dengan cara pembentukan dua kelompok yang akan dibandingkan. Sampel ada dua bagian yaitu kelas eksperiment yang diberikan pembelajaran dengan media pembelajaran tiga dimensi dengan kelas control dengan pembelajaran konvensional dan tanpa adanya media pembelajaran tiga dimensi. Oleh karena itu, rancangan penelitian yang digunakan adalah nonequivalent control group design. Berikut iniadalah desain penelitian:

Tabel 1. Desain Penelitian

\begin{tabular}{llll}
\hline \multicolumn{1}{c}{ Kelas } & Pretest & Perlakuan & Posttest \\
\hline Kelas Eksperimen & $\mathrm{Y}_{1}$ & $\mathrm{X}_{1}$ & $\mathrm{Y}_{2}$ \\
Kelas Kontrol & $\mathrm{Y}_{1}$ & $\mathrm{X}_{2}$ & $\mathrm{Y}_{2}$ \\
\hline
\end{tabular}

Ket:

$\mathrm{Y}_{1}:$ Pemberian Pretest

$\mathrm{X}_{1}$ : Pembelajaran dengan media pembelajaran tiga diemensi

\author{
$\mathrm{X}_{2}$ : Pembelajaran dengan pembelejaran \\ konvensional \\ $\mathrm{Y}_{2}$ : Pemberiean Posttest
}


Jenis penelitian yang di gunakan akni metode kuantitatif yang di gunakan untuk memperoleh data dari hasil penelitian. Data kuantitatif diperoleh dari hasil belajar pesertadidik sebelum dan sesudah penggunaan media pembelejaran tiga dimensi. Data tersebut di dapatkan dari hasil tes pesrta didik. Pada penelitian ini, tes digunakan untuk mengukur hasil belajar pesertadidik kelas eksperiment dan kelas kontrol. Metode tes yang akan di gunakan adalah pretest dan posttest.

Populasi dalam penelitian ini adalah seluruh peserta didik SDI Sabilillah Cukir Diwek Jombang. Sampel yang digunakan adalah peserta didik kelas II A dan kelas II B SDI Sabilillah Cukir Diwek Jombang. Penelitian ini dilaksanakan di SDI Sabilillah Cukir Diwek Jombang. Penelitian ini dilaksanakan pada bulan Maret 2020 semester genap pada tahun pelajaran 2019/2020.
Instrumen tes yang akan di gunakan dalam penelitian ini ialah berupa test tertulis, tes ini menuntut peserta didik agar menjawab pertanyaan berdasarkan data yang ada. Soal tes yang terdapat di dalam penelitian ini di buat secara mandiri oleh peneliti dengan mengacu terhadap materi-materi yang telah di sampaikan untuk dijadikan soal-soal pretestdanposttest pada kelompokeksperimen juga kelompokkontrol dengan soal yangsama.

Pada suatu penelitian point utama dalam penelitian ialah valid, realibel serta objektif. Instrument yang sudah dinyatakan valid, berarti siap di berikan kepada responden pada saat penelitian. Validitas di dalam penelitian ini di hitung dengan Microsoft excel. Uji validitas dalam penelitian ini menggunakan kuisioner yang di isi oleh tiga ahli. Data tersebut akan dikalkulasi untuk dihitung kevalidannya.

Tabel 2. Data Uji Validitas Media Pembelajaran

\begin{tabular}{ccccc}
\hline No & Reponden & Jumlah Skor & Nilai & Keterangan \\
\hline 1 & 1 & 21 & 65.7 & Valid \\
2 & 2 & 30 & 97.7 & Valid \\
3 & 3 & 28 & 87.5 & Valid \\
\hline
\end{tabular}

Tabel 3. Data Uji Validitas RPP

\begin{tabular}{ccccc}
\hline No & Reponden & Jumlah Skor & Nilai & Keterangan \\
\hline 1 & 1 & 24 & 66.6 & Valid \\
2 & 2 & 32 & 88.8 & Valid \\
3 & 3 & 33 & 91.6 & Valid \\
\hline
\end{tabular}

Tabel 4. Data Uji Validitas Butir Soal

\begin{tabular}{ccccc}
\hline No & Reponden & Jumlah Skor & Nilai & Keterangan \\
\hline 1 & 1 & 24 & 75 & Valid \\
2 & 2 & 30 & 93.7 & Valid \\
3 & 3 & 29 & 90.6 & Valid \\
\hline
\end{tabular}

Teknik pengumpulan data yakni cara yang berguan untuk pengumpulan datayang akan dianalisis. Data yang dikumpulkan penlliti yakni berupa tes. Hasil belajar peserta didik dapat diuji dengan tes. Tes dilakukan secara bertahap yakni pretest dan posttest. Soal pretest dan posttest yang digunakan berbentuk pilihan ganda.

a. Pretest merupakan tes hasil belajar sebelum menggunakan media pembelajaran tiga dimensi. Hasil dari pretest digunakan sebagai nilai pretest. 
b. Posttest merupakan tes hasil belajar setelah menggunakan media pembelajaran tiga dimensi. Hasil dari posttest merupakkan nilai posttest.

Teknik yang digunakan adalah teknik analisis statistik komparatif, yakni dengan membandingkan hasil dari tes di kelas eksperimen setelah penerapan dengan hasil tes di kelas kontrol. Analisis data mengguanakn test-t. Tes-t adalah uji statistik yang diperuntukkan guna membandingkan atau membedakan apakah kedua variabel tersebut sama ataukah memiliki perbedaan (Sugiyono, 2017:95).

Ada dua syarat yang harus dilakukan sebelum melakukan uji test-t :

\section{a. Uji Normalitas}

Sebelum dilakukan analisis data dengan menggunakan t-tes, data tersebut terlebih dahulu di uji normalitas dengn bantuan aplikasi Ms.Excel.

Jika perhitungan diperoleh $t_{\text {hitung }}<t_{\text {tabel }}$, maka sampel dinyatakan memiliki data yang normal. Jika data yang di dapatkan sudah berdistribussi normal, maka langkah selanjutnya yakni test-t.

\section{b. Uji Homogenitas}

Uji homogenitas dialakukan untuk mengetahui kemampuan awal peserta didik sama atau tidak. Uji homoginitas menggguankan uji $\mathrm{F}$. Bila pernghitungan yang didapatkan $\mathrm{F}_{\text {hitung }}<\mathrm{F}_{\text {tabel }}$, maka sampel yang diambil dinyatakan homogen.

\section{c. Uji Hipotesis}

Uji hipotetsis ini dilakuakn untuk mengetahui rata-rata kemampuan peserta diidk sebelum dan juga sesudah melakukan pembelajaran dengan menggunakan media pembelajaran tiga dimensi di kelas eksperiment dan juga untukmengetahui perbedaan rata-rata kemampuan peserta didik sebelum dan juga sesudah melakukan pembelajaran dengan pembelajaran konvensioanl di kelas kontrol.

\section{HASIL DAN PEMBAHASAN}

Hasil Pembelajaran Bahasa Indonesia Pada Siswa Kelas II SDI Sabilillah di Kelas Kontrol

Pelaksanaan pembelajaran di kelas kontrol dilaksanakan pada hari Kamis tanggal 5 Maret 2020. Setelah dilakukan pretes, selanjutnya peneliti melakukan posttest diakhir pembelajaran.
Untuk mengetahui kenormalan data yang sudah di dapatkan peneliti menggunakan uji normalitas. Hasil penghitunngan uji normalitas diatas diperoleh $\mathrm{X}_{\text {hitung }}$ pretest kelas kontrol adalah -20.624668 dan $X_{\text {hitung }}$ posttest kelas kontrol adalah -4.4655265 , sedangkan $X_{\text {tabel }}$ didapat dari rumus excel $=$ CHIINV dengan $\alpha=0.05$ dan banyak kelas 6 dan didapat $X_{\text {tabel }}=11.0704$ untuk pretest dan posttest kelas kontrol dan kelas eksperimen. Dikarenakan $\mathrm{X}_{\text {hitung }}<\mathrm{X}_{\text {tabel }}$ maka dapatdisimpulkan bahwadata pretestdanposttest kelas kontrol berdistribusi normal.

Untuk uji hipotesis, $\mathrm{t}_{\text {hitung }}$ akan dibandingkan dengan $t_{\text {tabel }}$.Dari hasil perhitungan diperoleh $\mathrm{t}_{\text {hitung }}=3.67$, dan $\mathrm{t}_{\text {tabel }}$ dengan $\alpha=0.05$ dan $\mathrm{dk}=\mathrm{n}-1=20-1=19$ diperoleh $\mathrm{t}_{\text {tabel }}$ sebesar 2.093. Karenat $_{\text {hitung }}>\mathrm{t}_{\text {tabel }}$, maka Ha diterima sehingga dinyatakan terdapat perbedaan rata-rata atau peningkatan pada hasil belajar Bahasa Indonesia kelas 2 SDI Sabilillah sesudah menggunakan pembelajaran konvensional.

\section{Hasil Pembelajaran Bahasa Indonesia Pada Siswa Kelas II SDI Sabilillah di Kelas Eksperiment}

Pelaksanaan pembelajaran di kelas eksperiment dilaksanakan pada hari Jum'at tanggal 6 Maret 2020. Setelah dilakukan pretes, selanjutnya peneliti melakukan posttest diakhir pembelajaran.

Untuk mengetahui kenormalan data yang sudah di dapatkan peneliti menggunakan uji normalitas. Hasil penghitungan uji normalitas diatas diperoleh $\mathrm{X}_{\text {hitung }}$ pretest kelas kontrol adalah -22.767587 dan $\mathrm{X}_{\text {hitung }}$ posttest kelas kontrol adalah -21.404218 sedangkan $\mathrm{X}_{\text {tabel }}$ didapat dari rumus excel $=$ CHIINV dengan $\alpha=0.05$ dan banyak kelas 6 dan didapat $\mathrm{X}_{\text {tabel }}=11.0704$ untuk pretest dan posttest kelas kontroldan kelaseksperimen. Dikarenakan $X_{\text {hitung }}<X_{\text {tabel }}$ maka dapat disimpulkan bahwa data pretest dan posttest kelas kontrol berdistribusi normal.

Karena $t_{\text {hitung }}>t_{\text {tabel }}$ atau $3.73>2.093$ maka Ho ditolak dan Ha diterima, artinya ada perbedaan antara pretest dan posttest pada kelas eksperimen, sehingga dapat dinyatakan bahwa terdapat pengaruh positif pembelajatan bahasa Indonesia 
dengan menggunakan media pembelajatan tiga dimensi.

Pengaruh penggunaan media pembelajaran tiga dimensi pada kelas II dapat disimpulkan berdasarkan penelitian yang dilakukan dari kelas kontrol dan kelas eksperimen. Kelas kontrol adalah kelas yang dalam penelitian ini pembelajarannya menggunakan metode konvensional. Kelas eksperimen adalah kelas yang dalam penelitian ini pembelajarannya menggunakan media pembelajaran tiga dimensi. Sebelum pembelajaran dilaksanakn terlebih dahulu dilakukan pretest pada kelas kontrol dan kelas ekperimen.

Jika kita membandingkan t-test di kelas eksperiment dan kelas kontrol, yaitu (3.73) > (3.67) dapat dilihat bahwa terdapat perbedaan antara kelas eksperimen denganmenggunakan media pembelejaran tiga dimensi dankelas kontrol denganmenggunakan pembelajaran konvensional, dan pengaruh penggunaan media tiga dimensi lebih besar daripada pada pembelajaran konvensional.

Tabel 5. Hasil Uji T Kelas Kontrol dan Kelas Eksperiment

\begin{tabular}{cccccc}
\hline Kelompok & Kelas & $\mathbf{N}$ & Mean & $\mathbf{t}_{\text {hitung }}$ & $\mathbf{t}_{\text {tabel }}$ \\
\hline Kontrol & Pretest & 20 & 49.5 & 3.67 & 2.093 \\
& Posttest & 20 & 70.25 & & \\
Eksperimen & Pretest & 20 & 50 & 3.73 & 2.093 \\
& Posttest & 20 & 80.25 & & \\
\hline
\end{tabular}

\section{SIMPULAN DAN REKOMENDASI}

Terdapat pengaruh positif pada pembelajaran konvensioanal pada kelas kontrol, dengan uji t pada pembelajaran konvensional di kelas kontrol dengan $t_{\text {hitung }}(3.67)>t_{\text {tabel }}$ (2.093). Terdapat pengaruh positif yang dibuktikan dengan uji t pada pembelajaran menggunakan media pembelajaran tiga dimensi dengan hasil $t_{\text {hitung }}$ (3.73) $>\mathrm{t}_{\text {tabel }}(2.093)$. Hasil uji t pada kelas kontrol dengan pembelajaran konvensional sebesar 3.67. Sedangkan hasil uji $\mathrm{t}$ pada kelas eksperiment dengan menggunakan media pembelajaran tiga dimensi sebesar 3.73. Dengan demikian, dapatdisimpulkan bahwa terdapat pengaruh yang positif penggunaanmedia pembelajaran tiga dimensi terhadap hasil belajar bahasa Indonesia pada kelas II SDI Sabilillah.

\section{DAFTAR PUSTAKA}

Krisnawati, A. (2013). Penggunaan Media Tiga Dimensi Untuk Meningkatkan Hasil Belajar Di Sekolah Dasar. JPPGSD , 2-3.

Kurniawan, D. (2014). Pembelajaran Terpadu Tematik. Bandung: Alfabeta.
Marpaung, S. (2016). Pengembangan Media Pembelajaran Bahasa Indonesia Berbasis Macromedia lash Profesional 8 Kelas V SD Swasta Namira. Jurnal Teknologi Informasi \& Komunikasi dalam Pendidikan, 30-31.

Septian, J. T. (2015). Pengaruh Pembelajaran Menggunakan Media Tiga Dimensi (3d)Terhadap Hasil Belajar Menggambar Dengan Perangkat Lunak Kelas XI Program Keahlian Teknik Gambar Bangunan. Jurnal Education Building , 74.

Sudjana, N. (2011). Dasar-dasar Proses Belajar Mengajar. Bandung: Sinar Baru Algesindo.

Sudjana, N. (2011). Penilaian Hasil Proses Belajar Mengajar. Bandung: PT Remaja Rosydakarya.

Sugiyono. (2017). Metode Penelitian. Bandung: Alfabeta.

Sugiyono. (2015). Metode Penelitian Pendidikan Kuantitatif, Kualitatif,dan $R \& D$. Bandung: Alfabeta. 
Jurnal PAJAR (Pendidikan dan Pengajaran)

Volume 4 Nomor 4 Juli 2020 | ISSN Cetak : 2580 - 8435 | ISSN Online : 2614 - 1337

DOI : http://dx.doi.org/10.33578/pir.v4i5.8101

Sugiyono. (2017). Statistika Untuk Penelitian.

Bandung: Alfabeta.

Wati, E. R. (2016). Ragam Media Pembelajaran. Jogjakarta: Kata Pena.

Yunita Retnani Lestari, d. (2015). Pembelajaran Apresiasi Sastra di Sekolah Dasar. Jurnal Elementary, 137-138.

Yunita Retnani Lestari, d. (2018). Peningkatan Proses Dan Hasil Belajar Muatan Bahasa Indoneisa Melalui Model Pembelajaran Numbered Head Together Pada Siswa Kelas 1 SD Ledok 0 Salatiga. Kalam Cendikia, 3-4. 